\title{
The use of nominal group technique in identifying community health priorities in Moshi rural district, northern Tanzania
}

\author{
E.A. MAKUNDI ${ }^{1 *}$, R. MANONGI ${ }^{2}$, A.K. MUSHI ${ }^{1}$, M.S. ALILIO ${ }^{1}$, T.G. THEANDER ${ }^{3}$, \\ A.M. RØNN ${ }^{3} \&$ I.C. BYGBJERG ${ }^{3}$ \\ ${ }^{\prime}$ National Institute for Medical Research, P.O. Box 9653, Dar es Salaam, Tanzania \\ ${ }^{2}$ Kilimanjaro Christian Medical Centre College, Tumaini University, Moshi, Tanzania \\ ${ }^{3}$ Centre for Medical Parasitology, University of Copenhagen, Denmark
}

\begin{abstract}
This article highlights issues pertaining to identification of community health priorities in a resource poor setting. Community involvement is discussed by drawing experience of involving lay people in identifying priorities in health care through the use of Nominal Group Technique. The identified health problems are compared using four selected village communities of Moshi district in Kilimanjaro region, Tanzania. We conducted this study to trace the experience and knowledge of lay people as a supplement to using 'health experts' in priority setting using malaria as a tracer condition. The patients/caregivers, women's group representatives, youth leaders, religious leaders and community leaders/elders constituted the principal subjects. Emphasis was on providing qualitative data, which are of vital consideration in multi-disciplinary oriented studies, and not on quantitative information from larger samples. We found a high level of agreement across groups, that malaria remains the leading health problem in Moshi rural district in Tanzania both in the highland and lowland areas. Our findings also indicate that 'non-medical' issues including lack of water, hunger and poverty heralded priority in the list implying that priorities should not only be focused on diseases, but should also include health services and social cultural issues. Indeed, methods which are easily understood and applied thus able to give results close to those provided by the burden of disease approaches should be adopted. It is the provision of ownership of the derived health priorities to partners including the community that enhances research utilization of the end results. In addition to disease-based methods, the Nominal Group Technique is being proposed as an important research tool for involving the non-experts in priority setting in Tanzania.
\end{abstract}

Key words: health, priority setting, lay people, nominal group technique, Tanzania

\section{Introduction}

Health systems in low-income countries are facing pressing problems, including high incidences of communicable diseases and a rising prevalence of chronic diseases while having limited resources for health care. In such a complex health arena, decision making in health care is faced with great challenges. There are many attempts to quantify the burden of disease and estimate costs and outcomes for different interventions aimed at reducing this burden and to improve efficiency in service delivery and to reassure more equity among users.

As a part of multi-sectoral reforms, Tanzania is currently implementing a Health Sector Reform (HSR) based on decentralisation and devolving power to districts $(\mathrm{MoH}, 1999)$. In this case, there is a need to develop good methods for involving the communities in priority setting. One concern now is the need for broader representation in the priority setting process to get a more socially representative picture expressing views of decision makers and lay-people's preferences in order to increase the quality and rationality of demand.

Priority setting is a process by which policy makers and community representatives rank health problems by order for the allocation of the limited resources so that the joint efforts result in positive and significant health changes and reduction in health problems (GFHR, 2000).

Assessment of community values is necessary both for measurement of burden of disease and resource allocation in order to make informed choices for health policy priorities. The importance of measuring individual preferences is well recognised among some health professionals, but using patients' or society's values in decisionmaking is far from a common practice (Froberg \& Kane, 1989).

Recently there has been a growing concern in public health and health economics that health state valuation measures should reflect the perceptions of the lay public, including patients (Nord, 1992; Gill

*Correspondence: Emmanuel Makundi; Email: emakundi@nimr.or.tz, elirurr@hotmail.com 
\& Feistein, 1994; Leplege \& Sonia, 1997). Some scholars argue that quality of life can be suitably measured only by determining the opinions of patients and thereby supplementing the instruments developed by 'experts' (Nord, 1992). Many valuation techniques consist of abstract thought exercises in which people assign weights to life years in different health states. Several valuation techniques are currently in use including the simple rating scale, visual analogue scale, magnitude estimation, standard gamble, time trade-off and person trade-off. These techniques have been compared in several studies and a considerable difference in results has been observed (Torrance, 1986; Froberg \& Kane, 1989; Nord, 1992).

One of the approaches to quantifying disease burden in human populations for priority setting is the use of Disability Adjusted Life Years (DALYs) (Murray \& Lopez, 1996). DALYs provide a framework for different professions in determining priorities in health care and evaluating efficacy of interventions since they employ a time-based measure that allows comparability across diseases, risk factors and between morbidity and mortality (Murray \& Lopez, 1996). Just like Quality Adjusted Life Years (QALYs), DALYs combine information about quality and quantity of life into a single number. The QALY approach uses weights on a scale going from 0 to 1 , 'zero' for "death" and 'one' for "full health." In the DALY approach, the scale is actually reversed where 'dead' scores one and 'healthy' scores zero (Nord, 1999). The purpose of health state valuation in the context of burden of disease research is to get additional information on non-fatal health outcomes on human populations (Murray \& Lopez, 1996). In the DALY development the person trade-off valuation method is used to generate disability weights by a panel of 'health experts' who are considered to be familiar with health outcomes with regard to relative ranking of health states in health care.

Several scholars have expressed their concerns regarding conceptual and methodological problems regarding the DALY approach (Anand \& Hanson, 1997; Sayers \& Fliedner, 1997; WHO, 1998; Arnesen \& Nord, 1999). One of the concerns is a need for broader representation in the DALY valuation methodology, to get a more socially representative picture expressing a particular society's' preferences (WHO, 1998). Another issue in the DALY calculation is the fact that, just like in many other health state valuation studies the person trade-off method is based on proxies where the subjects are asked to consider states that they have not experienced themselves (Nord, 1992).

Various studies have shown that non-health professionals in resource poor settings are able to draw reasoned conclusions and rank different disabilities and conditions in a rational and logical fashion (WHO, 1998). One challenge facing health sectors, particularly in resource poor settings, is to integrate the perspectives of marginalized groups and communities within the policy making and priority setting process.

This study was motivated by these concerns and used the nominal group technique to assess societal preferences to reflect 'burden of disease' in the valuation process. The main objective of the study was to determine the usefulness of the nominal group technique in eliciting societal preferences of health problems, and to assess if the technique would yield consistent ranking of health problems between different groups from a community of lay people in Moshi Tanzania. The study attempted to compare these problems across strata and gender and finally to orienting the district health managers on this particular tool for articulating community views regarding various problems of health in the district.

This study also supposed to complement data obtained among caretakers of children admitted to hospital with malaria, and from studies undertaken on quality of health services by observing health facilities at primary health care and referral hospital levels, in the Kilimanjaro Region (Manongi et al., 2005a, b).

\section{Materials and Methods}

\section{Study site and population}

This study was carried out in Moshi district in northern Tanzania and involved two communities, one in a rural highland area in Okaoni Ward, Kibosho Division and another in a semi-urban lowland area in Mabogini Ward, Arusha Chini Division. The study subjects included community leaders/elders, patients or caregivers, religious leaders, youth leaders and women group 
representatives living in two communities. A "ward" is defined as a collection of several hamlets with same geographical location. Okaoni Ward represents a community with relatively high economic status, while Mabogini Ward represents relatively low economic status community in Tanzania as reflected by the type of housing, cash crops grown and availability of social services basing on composite depravation index for regions of 1999. The study population was made up of various tribes, Chagga and Pare been the majority. The inhabitants of highlands are mainly the Chagga while those of lowland consist of 64 various tribes from all over Tanzania (Talle et al., 1995).

\section{Sampling and selection of respondents}

The study communities were selected through a multi-stage sampling technique. Initially, the district was divided into two strata of highland and lowland. In each stratum, one ward was randomly selected. Thereafter, the names of all the villages in the selected wards were written on small pieces of paper and then put in a basket. The pieces of paper were then shuffled and two villages were randomly selected in each site.

Participants in the nominal group technique were selected purposively in collaboration with key informants in the study areas. All adults (>18years) were eligible to participate. A key informant constitutes an important source of information in qualitative studies. A key informant was considered as a member of the study population who offered to inform or educate the researcher on a given subject of investigation (Coreil, 1995; Babbie, 1998). Key informants were identified when researchers were developing rapport in the study communities. Selection of participants in this study was done through a discussion with two key informants and a researcher.

In total there were eight groups, two in each village, one group consisting of men alone while the other consisting of women. The final number of participants included in this study varied slightly by each group but essentially the quota of ten was achieved in each group.

\section{Nominal group technique}

The nominal group technique is a structured form of brainstorming. It consists of several people who are prepared to work as a team to resolve a problem. The sharing of ideas (which are anonymously submitted) promotes a sense of involvement and motivation within the group (Delbecq et al., 1976). The technique was carried out in a group session that lasted on average 90 minutes. One discussion session was done under a tree in the village, other two in the meeting room at the village office and the rest inside classrooms in nearby primary schools. Each group was presented with a brief overview of the exercise and its purpose. Kiswahili, the national language of Tanzania, was used in the group sessions because it is well understood in the study areas.

One researcher and research assistant facilitated the conduction of nominal group technique protocol in assessing community preferences. In addition, one district council health management team (CHMT) member attended the sessions so as to gain some experience, thus strengthening the capacity of the district in assessing community problems. The group sessions were divided into four stages. Initially, each respondent identified and ranked disease, service and social-cultural problems individually. Thereafter, this information was analysed and the ranking presented to the group. Then, a discussion session was conducted to get the groups' ranking and adjustment of the ranking in an attempt to reach a group consensus. Thereafter, the leading 10 conditions were presented to the participants in a circular form as opposed to linear presentation in order to reduce bias. In the final step, assuming that full consensus was not achieved, voting was used to elicit majority views and also allowing disagreement to be expressed. Voting was done through self-elimination method.

\section{Data analysis}

Individual ranks from participants were collated and the scores from each condition noted. These scores were added to get mean values. The ranking order was achieved by arranging the mean values in ascending order from 1-10 for disease problems, 15 for service problems and 1-3 for socio-cultural problems. The condition scoring lowest value was considered as most severe, while the one scoring largest value was taken as least severe condition. 


\section{Results}

Table 1: Disease problems in the highland villages of Moshi and Tanga collaboration

\begin{tabular}{lllll}
\hline Order & \multicolumn{2}{c}{ Kitandu village } & \multicolumn{2}{c}{ Dakau village } \\
& Male Group & Female Group & Male Group & Female Group \\
\hline 1. & Malaria & Malaria & Malaria & Malaria \\
2. & AIDS & AIDS & AIDS & Rheumatism \\
3. & Hypertension & Hypertension & Hypertension & Hypertension \\
4. & Tuberculosis & Diarrhoea & Cancer & Diabetes \\
5. & Diabetes & Eye diseases & Eye diseases & Diarrhoea \\
6. & Bacillary dysentery & Diabetes & Diarrhoea & Worms \\
7. & Typhoid & Tuberculosis & Diabetes & Tuberculosis \\
8. & Hepatitis & Rheumatism & Asthma & Eye diseases \\
9. & Rheumatism & Cholera & Meningitis & Measles \\
10. & Dental carries & Measles & Cholera & AIDS \\
\hline
\end{tabular}

The same exercise was repeated for health service and social-cultural problems. Then, results from voting exercises were tabulated to facilitate group comparisons. villages (Table 1). In the lowland, schistosomiasis was voted as second leading disease in all groups except one (Table 2). AIDS ranked higher except for Chekereni village.

Table 2: Disease problems in the lowland villages

\begin{tabular}{lllll}
\hline Order & \multicolumn{2}{c}{ Chekereni village } & \multicolumn{2}{c}{ Mvuleni village } \\
& Male Group & Female Group & Male Group & Female Group \\
\hline 1. & Malaria & Malaria & Malaria & Malaria \\
2. & Schistosomiasis & Schistosomiasis & Schistosomiasis & AIDS \\
3. & Amoebiasis & Amoebiasis & AIDS & Typhoid \\
4. & Typhoid & Worms & Typhoid & Diarrhoea \\
5. & Diarrhoea & Hook worms & Tuberculosis & Cholera \\
6. & Hook worm & Typhoid & Diarrhoea & Amoebiasis \\
7. & Cancer & Bacillary dysentery & Cholera & Tuberculosis \\
8. & Tuberculosis & Diarrhoea & Meningitis & Schistosomiasis \\
9. & AIDS & AIDS & Eye diseases & Eye diseases \\
10. & Gonorrhoea & Tuberculosis & Convulsion & Measles \\
\hline
\end{tabular}

A total of 88 participants (44 females and 44 males) were involved in eight group sessions in the selected villages. In each village, men and women attended different group sessions to discuss the same themes. As homogeneous groups, the participants had more freedom to discuss different issues among themselves with a broad view of social and cultural values in their areas.

Overall, malaria featured as the topmost disease in all group sessions held in the highland and lowland areas. With exception of rheumatism that was mentioned in female group session at Dakau village, AIDS and hypertension were ranked as the second and third leading health problems respectively, by most of the groups in highland
Generally, poverty and unclean environment were identified at different places within and between lowland and highland strata, as leading problems facing health services (Tables 3 and 4). When respondents were asked what they meant by 'poverty', they considered lack of financial resources to pay for health services when they fall ill. Other problems included lack of drugs, lack of equipment and qualified personnel in public health facilities. Generally, there was a common feeling among male and female participants within strata (highland and lowland), on socio-cultural problems. In the highlands, gender discrimination featured as a leading problem facing women, in the form of female genital mutilation and widow inheritance. 
Table 3: Health service problems in the highland villages

\begin{tabular}{lllll}
\hline Order & $\begin{array}{l}\text { Kitandu village } \\
\text { Male Group }\end{array}$ & Female Group & $\begin{array}{l}\text { Dakau village } \\
\text { Male Group }\end{array}$ & Female Group \\
\hline 1. & $\begin{array}{l}\text { Poor health } \\
\text { education }\end{array}$ & Dirty environment & Poverty & Lack of money \\
2. & $\begin{array}{l}\text { Poverty } \\
\text { Lack of drugs }\end{array}$ & $\begin{array}{l}\text { Lack of money } \\
\text { Unsafe water }\end{array}$ & $\begin{array}{l}\text { Lack of medicine } \\
\text { Dirty } \\
\text { environment } \\
\text { Poor nutrition }\end{array}$ & $\begin{array}{l}\text { Dirty environment } \\
\text { Poor nutrition }\end{array}$ \\
3.5 & Unsafe water & $\begin{array}{l}\text { Lack of hospital } \\
\text { equipment } \\
\text { Lack of skilled health } \\
\text { staff }\end{array}$ & Toilet misuse & $\begin{array}{l}\text { People don't attend } \\
\text { hospitals }\end{array}$ \\
\hline
\end{tabular}

Table 4: Health Service Problems in the lowland villages

\begin{tabular}{|c|c|c|c|c|}
\hline \multirow[t]{2}{*}{ Order } & \multicolumn{2}{|l|}{ Chekereni village } & \multicolumn{2}{|l|}{ Mvuleni village } \\
\hline & Male Group & Female Group & Male Group & Female Group \\
\hline 1. & Poverty & Poverty & Dirty environment & $\begin{array}{l}\text { Poor health } \\
\text { education }\end{array}$ \\
\hline 2. & Dirty environment & Dirty environment & Dirty environment & Lack of hospital \\
\hline 3. & Poor nutrition & Unsafe water & Poverty & Poverty \\
\hline 4. & Lack of medicine & Mosquito nuisance & Lack of hospital & $\begin{array}{l}\text { Dirty } \\
\text { environment }\end{array}$ \\
\hline 5. & Corruption & Lack of health facility & Unsafe water & Unsafe water \\
\hline
\end{tabular}

Superstition (belief in and practice of witchcraft) was voted as the second leading problem among the communities in Okaoni in the highlands. On the other hand, the residents in the lowlands voted for superstition, female genital mutilation and widow inheritance as the leading socio-cultural problems in their societies. Other problems included food taboos and sacrife rituals.

\section{Discussion}

Like in many other districts in Tanzania, malaria is the most important public health problem among the population in Moshi district (Magesa et al., 2001). The ranking of malaria as the topmost health problem was substantiated by the district annual report for 2003 (data not shown) and previous observations by Makundi et al. (2004). It was interesting to note that malaria was an equally important health problem among residents of the highland areas. Highland areas were traditionally considered to be malaria free zones. However, the disease appears to increasingly affect highland areas given migration trends for farmers who move to lowlands especially during cereal farming seasons. Similar situations have also been described in other districts in Tanzania (Mboera, 2004; Maegga et al., 2005).

HIV/AIDS was the second most important health problem among most of the communities in the district. Similar findings have been reported by other authors in Tanzania and other sub-Saharan African countries (Murray \& Lopez, 1996; Manongi, 2005a). This suggests that the indices used in our study provide a rapid assessment of health problems among communities of Tanzania. More interestingly, one female group in lowlands ranked HIV/AIDS as a second leading disease problem, and it was ranked high by majority of groups in highland strata. HIV/AIDS especially in the highland area was considered as posing more problems to the families than other disease conditions. Indeed, during the discussions HIV/AIDS was considered as a priority problem as many families had members who travel to various parts of the country for economic purposes and this was associated with the introduction of the disease 
in their villages. Many deaths resulting from AIDS consisted of individuals brought from other areas of Tanzania and a nearby Kenya for burial. Evidence from a nearby Hai district with similar social and cultural roots shows increasing cases of HIV/AIDS deaths coming from outside the district especially from major towns and mining centres (MoH, 1997). From the above description it seems that mobility is an important risk factor for HIV infection (R. Isingo, unpublished).

Schistosomiasis was voted as the second leading disease problem in three out of four group sessions held in lowlands. Schistosomiasis in the lowland area and was associated with the ongoing irrigation activities. Studies by Kiwelu and her colleagues (1992) indicated high prevalence of schistosomiasis in the area. Non-communicable diseases, like hypertension and diabetes were only mentioned in the highland. This could be explained by the social economic differences between highland and lowland areas. Majority of highland inhabitants are Chaggas and are known for their economic entrepreneurship within the country (Talle, 1995) which is likely to be associated with life-styles that predispose them to such ailments.

Regarding socio-cultural health issues, discussions revolved in conceptualising health in a holistic approach, where a health problem is seen in both physiological and social-cultural perspective. In attempt to conceptualise health, it emerged during group discussions that diseases do not just occur 'come from heaven'. Instead they are caused by lack of health facilities, and existence of socio-cultural beliefs such as wife inheritance, which could lead to increase in burden of disease. The problem of female genital mutilation is increasingly becoming of great concern especially in the highland areas.

Lack of medical supplies, equipment and qualified personnel in public health facilities observed in this study is common in many districts of Tanzania, including the neighbouring Moshi Municipality and Hai district (Manongi, 2005a, b).

Since this study sought to explore the application of the qualitative nominal group technique on a sample of community representatives in setting health priorities, this technique appears to be a useful methodological approach to elicit societal value preferences of health conditions in a community of lay people. As a tool for rapid assessment, the technique was well understood and appreciated by respondents as voice of each member was equally represented.

The use of the nominal group technique in identifying problems and setting priorities in health care has been appreciated (McMurray, 1994; Maclachlan, 1996; Redman et al., 1997). The stability of results in the nominal group technique observed in this study has been reported from other studies using similar technique in identifying health priorities and in valuation exercises (Redman et al., 1997; Ustun et al., 1999). In this particular study, using simple ranking and voting exercises in the nominal group technique, a consistent ranking of health conditions between different groups from a community of lay people in Tanzania was observed.

The advantage of the the use of the nominal group technique as observed in this study is the interactive nature of the group sessions and the increased freedom of judgement as indicated through voting. The most interesting stage was the voting exercise where the participants were highly excited. The secret voting process was democratic, which seemed to enhance freedom of expression of ideas. The group sessions were done on the basis of deliberation, where a consensus is achieved on the basis of discussion, which could be closer to person trade off method described elsewhere (Murray \& Lopez, 1996). In addition, the fact that the outcomes of all procedures were clearly documented and understood by all members emphasised the relevance of the procedure. The technique therefore offers a unique opportunity for discussion and achieving a consensus through voting in the group.

It is important to consider in this study that the nominal group technique explicitly requires each member of the group to have an equal input in both the initial individual ranking and the voting stages. People feel more commitment to a group if they have a chance to influence its thinking (Walton, 1985). It is important to note that, while focus group discussions may allow some individual expression, some individuals may be more reluctant to participate, which may lead to some participants dominate the discussion. This give the facilitator a challenge to manage the group through avoiding eye contact and encouraging those who are reluctant to speak up. It may be argued that some participants may not speak out at all during focus group 
discussion, something which may not occur during nominal group technique as voice of each member is expressed through voting. In addition, the technique gives an opportunity for participants and investigators in the same session to undertake two exercises at the same time, simple ranking and voting, and thereafter comparing the results. In other studies, such as those using survey techniques, while the informants provide vital information, sometimes they may not have the opportunity to see and compare results (Hardon, 2001).

One limitation of nominal group technique relates to the way the respondents were asked the questions, which may have caused framing effects in the valuation exercise. As noted earlier, the nominal group technique consisted of four steps namely: simple ranking, discussion, voting and comparison of results. Although respondents were asked to rank diseases according to severity, it seems they ranked according to disease prevalence where HIV/AIDS, malaria and diarrhoea were given more priority. However, although the ranking provides a rough indication of the "burden of disease" in the communities, it may not provide a ranking of people's perception of severity of diseases. Another limitation related to this method is the discussion session in the period between individual ranking and the voting exercise, which may have influenced the final voting judgement. On the other hand, the discussion session might be an advantage in the groups' deliberative process by reaching a consensus on the basis of discussion. This may be closer to the person trade-off-method used in the burden of disease study by Murray \& Lopez (1996).

The technique has identified leading problems and shown a relatively high degree of agreement in preferences from two communities of Moshi district in Tanzania. The findings suggest that malaria remains a foremost priority disease in the district. This approach was relatively easy to apply to a community of lay people. Though the methods of demonstrating the reliability and validity of the nominal group technique are not well established in other studies using the same technique, there was a considerable agreement in the ranking across the groups.

It must be stressed that nominal group technique is a form of focus group discussion, which includes voting and display of results. Despite the fact that many stages are involved, this technique uses less time (90 minutes in our study) than other types of group sessions, including focus group discussion which usually takes about 2 hours (Coreil, 1995). This method may be adapted to compliment the current burden of disease data used for priority setting in health care. Although it generates qualitative richness to a study, the technique may be inappropriate when used alone for generalisation as it only gives in-depth information for a small number of people. In addition, the nominal group technique methodology suits research that include both health professionals and users of the services, since it allows for free exchange of opinions and generation of idea within a structured and non-hierarchical discussion forum. It has a potential for utilization by health managers at the district level in identifying community priorities in the on-going reforms in Tanzania.

\section{Acknowledgements}

We are grateful to Regional Medical Officer, Kilimanjaro for his cooperation. We are highly indebted to District Health Management Team members and particularly the District Medical Officer of Moshi for facilitating the study. In addition, we wish to thank Mr. Rajab Nguluma, Ms. Wineaster Anderson and Ms. Hildegalda Mushi for their technical and field assistance. We also wish to thank the community representatives who volunteered their time and information. This study was financially supported by the Danish International Development Agency through the ENRECA project. 


\section{References}

Anand, S. \& Hanson, K. (1997). Disability-adjusted life years: a critical review. Journal of Health Economics 16, 685-702.

Arnesen, T. \& Nord, E. (1999). The value of DALY life: problems with ethics and validity of disability adjusted life years. British Medical Journal 319, 1423-1425.

Babbie, E., (1998). The Practice of Social Research. Wadsworth Publishing Company, ITP, 8th Edition.

Coreil, J. (1995). Group interview methods in community health research. Medical Anthropology 16,193-210.

Delbecq, A.L., Van de Van, D.H. \& Gustafson, D.H., (1976). Group Techniques for Program Planning: A Guide to Nominal Group and Delphi Processes. Glenview, 111: Scott, Foresman.

Froberg, D.G. \& Kane, R.L. (1989) Methodology for measuring health-state preferences- I: Measurement strategies; Journal of Clinical Epidemiology 42, 345-354.

Gill, T.M. \& Feistein, A.R. (1994) A critical appraisal of the quality of life measurements. American Journal of Medical Association 272, 24-31.

GFHR (2000) Global Forum for Health Research. The 10/90 Report on Health Research, Geneva.

Hardon, A.P., Boonmongkon, P., Streefland, P., Tan, M.L., Hongvitanata, van der Geest S., vanStaa, A., Varkevisser, C., Acuin, C., Chowdhur, M., Bhuiya, A., Sringeryuang, L., van Donger, E. \& Gerits, T. (2001) Focus group discussions. In: Applied Health ResearchAnthoropology of Health Care Het Spinhuis Publishers, Amstedam, pp. 235-243.

Kiwelu, I.E. \& Nyale, E. (1992) The effects of irrigation on the transmission of schistosomiasis in newly developed irrigation projects in Kilimanjaro region. Paper presented to Tanzania Public Health Association, 11th Annual Scientific Conference and General meeting, Dar es Salaam. Unpublished.

Leplege, A. \& Sonia, H. (1997) The problem of quality of life in medicine. American Journal of Medical Association 278, 47-50.

Maclachlan, M., (1996) Identifying problems in community health promotion: an illustration of the Nominal Group Technique in AIDS education. Journal of Royal Society of Health 116, 143-48.

McMurray, A. (1994) Three decision-making Aids: Brainstorming, Nominal Group Technique and Delphi Technique. Journal of Nursing Staff Development 10, 62-65.

Magesa, S.M., Mboera, L.E.G., Mwisongo, A.J., Kisoka, W.J., Mubyazi, G.M., Malebo, H., Senkoro, K.P., Mcharo, J., Makundi, A.J., Kisinza, W.N., Mwanga, J., Mushi, A.K., Hiza, P., Malecela-Lazaro, M.N. \& Kitua, A.Y. (2001) Major health problems in some selected districts of Tanzania. Tanzania Health Research Bulletin 3, (2), 10-14.

Manongi, R., Rønn, A., Dolmans, W. \& Bygbjerg, I.C. (2005a) Treatment paths and referral patterns among caretakers of under fives admitted with malaria at a regional and a district hospital in Kilimanjaro region, Tanzania. Report submitted to KCMC, through ENRECA/DANIDA.

Manongi, R., Nyindo, M., Rønn, A., Dolmans, W., Shao, J. \& Bygbjerg, I.C. (2005b) Evaluation of quality of health care delivery system at primary health care facilities: The case of malaria diagnosis and management in Kilimanjaro Region, Tanzania. Report submitted to KCMC, through ENRECA/Danida.

Mboera, L.E.G. (2004) Environmental and socioeconomic determinants of malaria epidemics in the highlands of Tanzania, Tanzania Health Research Bulletin 6, 11-17.

MoH (1997) Policy Implications of Adult Morbidity and Mortality Project (AMMP)). End of Phase one report. Ministry of Health. Dar es Salaam, Tanzania.

MoH (1999) Health Sector Reform Programme of Action. July 1999 to June 2000. Ministry of Health, Dar es Salaam, Tanzania.

MoH (2003) Final Report on Situational Analysis of 31 Districts for the Third Phase of Health Sector Reform. Ministry of Health, Dar es Salaam, Tanzania.

Murray, C. \& Lopez, A. (1996) Global Burden of Disease. World Health Organisation, Geneva.

Nord, E. (1992) Methods for quality adjustment of 
life years. Social Science and Medicine. 34, 559569.

Nord, E. (1999) Cost-Value Analysis in Health Care: Making Sense Out of QALYs. Cambridge University Press.

Redman, S., Carricks, Cockburn, J. \& Hirist, S. (1997) Consulting about priorities for the NHMRC National Breast Cancer Centre: how good is the nominal group technicque. Australia-New Zealand Journal of Public Health 21, 250-256.

Sayers, B.M. \& Fliedner, T.M. (1997) The critique of DALYs: a counter reply. Bulletin of World Health Organisation 75, 383-384.

Talle, A., Biswalo, P.M., Schreiner, A.H. \& Klepp, K.I. (1995) Young People at Risk: Fighting AIDS in Northern Tanzania. Scandnavian University Press, Oslo.

Torrance, G.W. (1986) Measurement of health state utilities for economic appraisal. Journal of Health Economics 5, 1-30.

Ustun, B.T., Rehm, J., Chtterji, S., Saxena, S., Trotter, R., Room, R. \& Bickenbarch, J. (1999) Multiple informant ranking of the disabling effects of different health conditions in 14 countries. Lancet 354, 111-115.

Walton, R.E. (1985) From control to commitment in work place Harvard Business Review: MarchApril, 77-84.

World Health Organization (1998) Report on the Informal Consultation on DALYs and Reproductive Health. Geneva. 